\title{
Superoxide radical induces sclerotial differentiation in filamentous phytopathogenic fungi: a superoxide dismutase mimetics study
}

\author{
loannis Papapostolou and Christos D. Georgiou
}

Correspondence

Christos D. Georgiou

c.georgiou@upatras.gr

Received 12 September 2009

Revised 10 November 2009

Accepted 8 December 2009

\author{
Department of Biology, Section of Genetics, Cell Biology and Development, University of Patras, \\ 26100-Patras, Greece
}

\begin{abstract}
This study shows that the superoxide radical $\left(\mathrm{O}_{2}{ }^{-}\right)$, a direct indicator of oxidative stress, is involved in the differentiation of the phytopathogenic filamentous fungi Rhizoctonia solani, Sclerotinia sclerotiorum, Sclerotium rolfsii and Sclerotinia minor, shown by using superoxide dismutase (SOD) mimetics to decrease their sclerotial differentiation. The production rate of $\mathrm{O}_{2}{ }^{-}$ and SOD levels in these fungi, as expected, were significantly lowered by the SOD mimetics, with concomitant decrease of the indirect indicator of oxidative stress, lipid peroxidation.
\end{abstract}

\section{INTRODUCTION}

Sclerotial differentiation is a primitive form of differentiation exhibited by certain phytopathogenic filamentous fungi. It is expressed by four main types of sclerotia (compact bodies of aggregated hyphae), which are loose, terminal, lateral-chained and lateral-simple. These types are represented mainly, but not solely, by Rhizoctonia solani, Sclerotinia sclerotiorum, Sclerotium rolfsii and Sclerotinia minor, respectively (Chet et al., 1967, 1969; Chet \& Henis, 1975; Le Tourneau, 1979; Willetts, 1971, 1978, 1997; Willetts \& Wong, 1980). These fungi are of great agricultural interest because they cause stem-rot diseases in a wide variety of economically important agricultural crops. Therefore, elucidating the mechanisms of sclerotium biogenesis of these fungi may lead to the development of non-toxic ways to combat plant diseases, which could be used as alternatives to the traditional toxic fungicides. Moreover, understanding sclerotial differentiation is very important because it will help to understand more complex forms of differentiation in other organisms as well as whether their mechanisms share common biochemical pathways.

It has been proposed that sclerotial differentiation is related to high oxidative stress (Georgiou, 1997), based on the finding that sclerotium biogenesis in $S$. rolfsii was accompanied by the accumulation of high levels of lipid peroxidation products. This finding has been supported by other studies that developed into a theory of oxidative stress as an inducer of sclerotial metamorphosis (Georgiou et al., 2006). Specifically, hydroxyl radical scavengers,

Abbreviations: BHA, butyl hydroxyanisole; HE, hydroethidium; HRP, horseradish peroxidase; MDA, malondialdehyde; SD, sclerotial initiation stage; SM, sclerotial maturation stage; SI, sclerotial development stage; SOD, superoxide dismutase; TBA, thiobarbituric acid; TBARS, thiobarbituric acid reactive species; UD, undifferentiated stage. vitamin $\mathrm{C}$ and $\beta$-carotene (both also acting as endogenous fungal antioxidants), decreased sclerotial differentiation in $S$. rolfsii, S. minor, S. sclerotiorum and $R$. solani. In more recent studies, we demonstrated a strong relationship between the thiol redox state of these fungi and their sclerotial differentiation (Patsoukis \& Georgiou, 2007a, b, 2008a, b, c). Specifically, in R. solani, S. rolfsii and S. minor, there was a decrease in the total amount of reduced thiols during transformation of the undifferentiated mycelium into sclerotium, which, for S. sclerotiorum was accompanied by an increase in the total oxidized components. Moreover, the antioxidant thiol redox state modulator $\mathrm{N}$-acetylcysteine inhibited sclerotial differentiation in $S$. rolfsii, $R$. solani and S. sclerotiorum.

Until now, our studies have associated only indirect indicators of oxidative stress with sclerotial differentiation. However, these indicators cannot conclusively establish such a relationship because they are affected by many metabolic processes that are not directly associated with oxidative stress. This fact necessitated the verification of this association with direct indicators of oxidative stress. Superoxide radical $\left(\mathrm{O}_{2}{ }^{-}\right)$is such an indicator because it is among the main initiators of oxidative stress (Halliwell \& Gutteridge, 1999). It is generated by reduction of molecular oxygen $\left(\mathrm{O}_{2}\right)$ by a single electron. The next reactive oxygen species produced is hydrogen peroxide $\left(\mathrm{H}_{2} \mathrm{O}_{2}\right)$, formed by $\mathrm{O}_{2}{ }^{--}$capturing an electron from another $\mathrm{O}_{2}{ }^{--}$molecule (dismutation reaction). Finally, the very potent hydroxyl radical is formed from $\mathrm{H}_{2} \mathrm{O}_{2}$ by capture of an electron from another $\mathrm{O}_{2}{ }^{-}$molecule or from free ferrous $\left(\mathrm{Fe}^{2+}\right)$ or cuprous $\left(\mathrm{Cu}^{1+}\right)$ ions (released, for example, from proteins oxidatively modified under abnormal conditions) (Halliwell \& Gutteridge, 1999). Organisms possess the antioxidant extra- and intracellular superoxide dismutase (SOD) to protect against the deleterious actions of $\mathrm{O}_{2}{ }^{-}$by catalysing its dismutation to $\mathrm{H}_{2} \mathrm{O}_{2}$ and $\mathrm{O}_{2}$. 
Intracellular SOD can be modulated by molecular genetics (introducing multicopy plasmids with a cloned SOD gene) or by certain chemicals (SOD mimetics) that mimic its activity (Day et al., 1995; Gardner et al., 1996; Kubota \& Yang, 1984; MacKenzie \& Martin, 1998; Mok et al., 1998; Yamada et al., 2003). In this work, we studied the effect of $\mathrm{O}_{2}{ }^{-}$in the degree of differentiation of S. rolfsii, S. minor, S. sclerotiorum and $R$. solani by modulating intracellular concentrations of $\mathrm{O}_{2}{ }^{--}$and SOD with the SOD mimetics Tiron and TEMPOL in relation to the indirect marker of oxidative stress, lipid peroxidation.

\section{METHODS}

Chemicals and reagents. Dihydroethidine (or hydroethidium, $\mathrm{HE}$ ), horseradish peroxidase (HRP), DNA type III (from salmon testes), dianisidine, SOD, EDTA, butyl hydroxyanisole (BHA), PMSF, Tiron, TEMPOL, thiobarbituric acid (TBA) and Dowex 50X8 (mesh 400) were from Sigma. DMSO, acetone, chloroform, acetonitrile, absolute methanol, ethanol, hydrogen peroxide $\left(\mathrm{H}_{2} \mathrm{O}_{2}\right)$, sodium cyanide, isobutanol, riboflavin, TCA and trifluoroacetic acid were from Merck. Hydrophobic Oasis HLB $1 \mathrm{~cm}^{3}(30 \mathrm{mg})$ extraction cartridges were from Waters Corp. All other reagents and solvents used were of the highest purity.

Fungal strains, growth conditions and developmental stages. R. solani strain (MUCL-30476) was obtained from the fungi bank of Mycothéque de l'Université Catholique de Louvain, Louvain-laNeuve, Belgium; S. sclerotiorum (MUCL-38483) was obtained from the Phytopathological Institute Culture Collection of Patras, Patras, Greece; S. rolfsii (ATCC-26325) was provided by the American Type Culture Collection; S. minor (BPIC-1682) was provided by Benakion Phytopathological Institute Culture Collection, Athens, Greece.

The fungal strains were grown in $25 \mathrm{ml}$ liquid medium (in Petri dishes) consisting of $0.1 \mathrm{M}$ glucose, $15 \mathrm{mM} \mathrm{NH}_{4} \mathrm{NO}_{3}, 2 \mathrm{mM} \mathrm{NaCl}$, $0.5 \mathrm{mM} \mathrm{MgSO}_{4}, 0.01 \mathrm{mM} \mathrm{FeCl}_{3}, 0.015 \mathrm{mM} \mathrm{MnCl}_{2}, 0.07 \mathrm{mM} \mathrm{ZnCl}_{2}$, $0.001 \mathrm{mM}$ thiamine and $0.1 \%(\mathrm{w} / \mathrm{v})$ yeast extract, in $10 \mathrm{mM}$ potassium phosphate buffer, $\mathrm{pH} 7$. The glucose $10 \times$ stock solution was separately sterilized to avoid formation of oxidizing Maillard reaction products (Bridson \& Brecker, 1970). Sterilization was performed for $15 \mathrm{~min}$ at $120{ }^{\circ} \mathrm{C}$ and at $2 \mathrm{~atm}$. Petri dishes were inoculated at their centres with an agar plug $(0.4 \mathrm{~cm}$ diameter $)$ taken from the growing margin of a $2.5 \mathrm{~cm}$ diameter fungal colony grown on potato dextrose agar. The inoculation day was counted as growth day 0 , and the colonies were grown at $23{ }^{\circ} \mathrm{C}$ and $65 \%$ relative humidity in single dish layers under a $12 \mathrm{~h}$ diurnal cycle with illumination $\left(0.040 \mathrm{mE} \mathrm{m}^{-2} \mathrm{~s}^{-1}\right)$ provided by Philips fluorescent lamp TLD 36W/965 with emission range of 400-800 nm.

Throughout their development, R. solani, S. sclerotiorum, S. minor and $S$. rolfsii exhibited developmental transition through identical stages, each with a characteristic morphology (Fig. 1). These were identified as the undifferentiated (UD), sclerotial initiation (SI), sclerotial development (SD) and sclerotial maturation (SM) stages. The UD stage is characterized by highly proliferating hyphae, the SI stage by the appearance of small distinct sclerotial initials formed from highly proliferating interwoven hyphae, the SD stage by the increase of sclerotium size and the SM stage is characterized by sclerotium surface delimitation, internal consolidation and melanin pigmentation, and is often associated with droplet excretion (Townsend \& Willetts, 1954). Developmental stages UD, SI, SD and SM for $R$. solani were reached in 3, 4, 5 and 6 days, respectively, for $S$. sclerotiorum in 3, 4, 7 and 9 days, respectively, for $S$. rolfsii in 4, 5, 7 and 9 days, respectively, and for $S$. minor in 3, 4, 6 and 7 days, respectively.

SOD mimetics Tiron and TEMPOL, used in this study, were prepared fresh as $1 \mathrm{M}$ (in $0.05 \mathrm{M} \mathrm{NaOH}$ ) sterile aqueous stock solutions of final $\mathrm{pH}$ 6.0. They were administered in the growth medium (also $\mathrm{pH}$ $\sim 6.0$ ) of the sclerotiogenic strains, 1 day before the end of the UD stage at maximum growth non-inhibiting concentrations. Tiron was administered in S. rolfsii and S. sclerotiorum at final concentrations of $0.5,1,5,10$ and $15 \mathrm{mM}$; TEMPOL was administered in R. solani and $S$. minor at concentrations of $1,2,3,4$ and $5 \mathrm{mM}$ and $0.01,0.03,0.07$, 0.1 and $0.3 \mathrm{mM}$, respectively. Tiron was used in $S$. rolfsii and $S$. sclerotiorum and TEMPOL in $R$. solani and S. minor because they were preferably absorbed by the particular strains, possibly due to strain specificity. Before administration, the net weight $(\mathrm{g})$ of the liquid cultures (including the wet weight of the fungal colony) was measured and equated with their volume $(\mathrm{ml})$, which was then used to determine the appropriate dilution of the stocks of the SOD mimetics required to bring the liquid cultures to the chosen concentrations. These maximum growth non-inhibiting concentrations were determined experimentally so as to not change the growth rate (colony dry weight per growth time) of the strains in the presence of the SOD mimetics (compared with growth in their absence).

Fungal tissue treatment. For R. solani, S. sclerotiorum and S. rolfsii, the assays were performed on the undifferentiated mycelial colony 1 day before the initiation of differentiation (UD stage), and separately on sclerotia representing the SI, SD and SM developmental stages. In the case of $S$. minor, the assays were performed on whole colonies at each of the differentiated sclerotial developmental stages since the separation of sclerotia from the surrounding mycelial matrix was not feasible due to the paucity of hyphae. Sclerotia, whenever possible, were separated from mycelia with sterile forceps and washed at least twice in 2-3 vols ice-cold phosphate-EDTA buffer [1 mM EDTA, $0.5 \mathrm{mM}$ PMSF, $0.3 \%$ absolute ethanol and $1 \mathrm{mM} \mathrm{BHA}$ (from $0.33 \mathrm{M}$ stock made in $100 \%$ absolute ethanol) in $10 \mathrm{mM}$ phosphate buffer, $\mathrm{pH}$ 7.2] per $\mathrm{g}$ fungal wet weight, and recovered by centrifugation at $6000 \mathrm{~g}$. Tissue pellets were mixed with 1-3 vols ice-cold phosphate-EDTA buffer per $g$ fungal wet weight, and were ground in a porcelain mortar in liquid nitrogen. The resulting homogenate was diluted with 2 vols $50 \mathrm{mM}$ phosphate buffer, $\mathrm{pH} 7.0$, centrifuged at $20000 \mathrm{~g}$ for $10 \mathrm{~min}$, and the resulting clear supernatant (cytoplasmic fraction) was subsequently used for the following assays, apart from the superoxide radical assay, where mycelial tissue and sclerotia were used directly.

Superoxide radical assay. Superoxide radical $\left(\mathrm{O}_{2}{ }^{-}\right)$was assayed by using a previously reported method (Georgiou et al., 2008), which is based on the reaction between $\mathrm{O}_{2}{ }^{-}$and $\mathrm{HE}$ that results in the formation of the specific product $2-\mathrm{OH}-\mathrm{E}^{+}$, the formation rate of which was measured and converted to superoxide production rate. Fungal tissue (mycelia/sclerotia with wet weight $\sim 0.1 \mathrm{~g}$ ) was incubated for $20 \mathrm{~min}$ in $1 \mathrm{ml}$ phosphate buffer $\left(50 \mathrm{mM} \mathrm{Na}_{2} \mathrm{HPO}_{4}\right.$, $\mathrm{pH}$ 7.0), supplemented with $20 \mu \mathrm{M} \mathrm{HE}$, under the same fungal growth conditions (temperature, light). The tissue was thoroughly washed with $10 \mathrm{M} \mathrm{HCl}$ and subsequently with $\mathrm{ddH}_{2} \mathrm{O} .2-\mathrm{OH}-\mathrm{E}^{+}$in the washed tissue was then extracted with $0.9 \mathrm{ml} 100 \%$ acetone, to which $0.01 \mathrm{ml} 10 \mathrm{M} \mathrm{NaOH}$ was added. 2-OH-E ${ }^{+}$was further isolated via cation and hydrophobic microcolumn chromatographies and quantified by the use of its fluorescence properties (in the presence and absence of DNA) and its reaction with hydrogen peroxide (catalysed by HRP). Fluorescence measurements were performed in a quartz microcuvette (internal dimensions $4 \times 4 \times 45 \mathrm{~mm}$ ) with its appropriate holder and a Shimadzu RF1501 spectrofluorometer set at $10 \mathrm{~nm}$ excitation/emission slit width and high sensitivity. 
(a) Undifferentiated-Differentiated
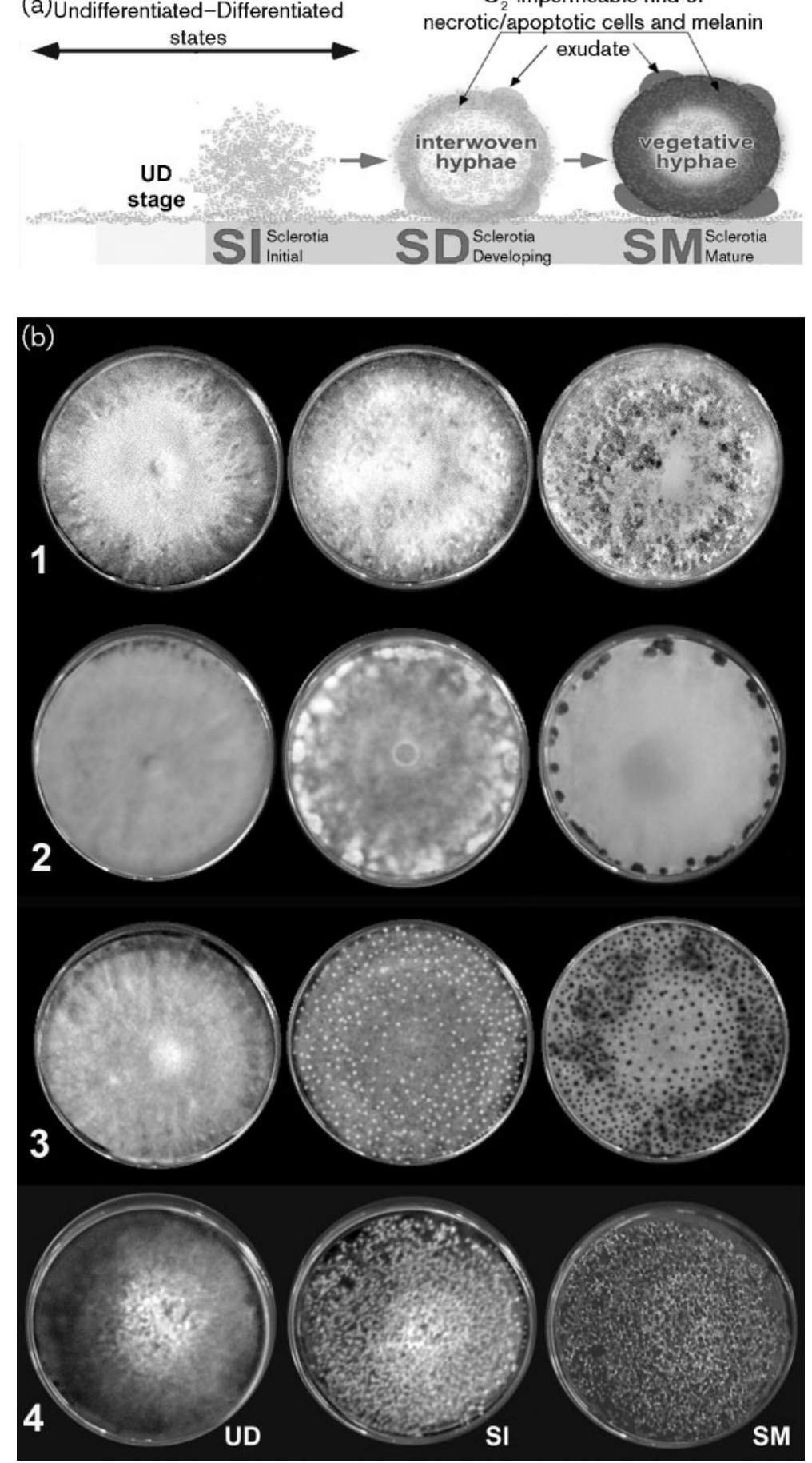

Fig. 1. (a) Schematic of sclerotium developmental stages SI, SD and SM (the differentiated states), starting from a UD colony (undifferentiated state); modified from the paper by Georgiou et al. (2006). (b) Developmental stages (UD, SI and SM) of the phytopathogenic fungi used in this study: 1, R. solani; 2, S. sclerotiorum; 3, S. rolfsii; 4, S. minor.
SOD assay. The assay is a modification of a previous one that is based on the SOD-inhibited reduction of oxidized dianisidine ( $\mathrm{Lu}$ et al., 2004; Misra \& Fridovich, 1977), which results from the reaction of its reduced form by the photochemically sensitized riboflavin. SOD increases the rate of the photooxidation of dianisidine due to the catalytic scavenging of $\mathrm{O}_{2}^{--}$, which would otherwise nullify the overall dianisidine photooxidation by reducing an intermediate dianisidine oxidation product (absorbing at $500 \mathrm{~nm}$ ). Illumination for the photochemical reactions was provided by a custom-made apparatus consisting of a circular fluorescent $22 \mathrm{~W}$ lamp (with internal diameter
$15 \mathrm{~cm}$, made by FUJI). The $1 \mathrm{ml}$ cuvette used for this assay was centred on a white plastic disk ( $6 \mathrm{~cm}$ diameter) that was mounted on top of a small electric fan $(8 \times 8 \times 2.5 \mathrm{~cm})$, which was fixed flat in the centre of the lamp (in order to keep a steady temperature, $26{ }^{\circ} \mathrm{C}$, around the cuvette).

The assay consists of mixing $0.2 \mathrm{ml}$ supernatant (or $0.2 \mathrm{ml}$ growth medium for measuring the extracellular SOD), at the required fungal developmental stage, with $0.22 \mathrm{ml} 0.06 \mathrm{mM}$ riboflavin stock (made fresh in the above phosphate buffer), $0.56 \mathrm{ml}$ phosphate buffer and 
$0.02 \mathrm{ml} 10 \mathrm{mM}$ dianisidine stock (made fresh in absolute ethanol and kept light-protected on ice). The assay mixture was kept in the illumination apparatus and its linear absorbance increase (versus time) was measured at $500 \mathrm{~nm}$ after $4 \mathrm{~min}$ (sample absorbance). This assay uses two blanks (A and B): blank A consisted of $0.2 \mathrm{ml}$ supernatant (or growth medium) mixed with $0.22 \mathrm{ml} 0.06 \mathrm{mM}$ riboflavin stock and $0.56 \mathrm{ml}$ phosphate buffer; blank B consisted of $0.2 \mathrm{ml}$ supernatant (or growth medium) mixed with $0.02 \mathrm{ml} 10 \mathrm{mM}$ dianisidine stock and $0.78 \mathrm{ml}$ phosphate buffer. The absorbance of both blanks was then measured at $500 \mathrm{~nm}$ after $4 \mathrm{~min}$, added together and then subtracted from the absorbance of the sample; this net absorbance difference rate (corresponding to the increase of oxidized dianisidine due to the presence of SOD in the sample) was converted to SOD units (U) from a standard curve $(0-3 \mathrm{U})$ made with pure bovine erythrocyte SOD. Absorbance measurements were done in a Shimadzu UV-1200 spectrophotometer.

Lipid peroxidation assay. Lipid peroxidation was assayed as TBA reactive species (TBARS) by a modified TBA-based method (Buege \& Aust, 1978; Zamora et al., 1997). Specifically, up to $0.15 \mathrm{ml}$ supernatant was mixed with $0.15 \mathrm{ml}$ TBA reagent (made as $0.5 \%$ $\mathrm{w} / \mathrm{v}$ TBA in $20 \% \mathrm{w} / \mathrm{v}$ TCA and $0.33 \mathrm{M} \mathrm{HCl}$ ) and BHA [ $2 \mu \mathrm{l}$ of $2 \%$ (w/v) made in absolute ethanol] was added to prevent artificial lipid peroxidation during the assay. The mixture was incubated at $100{ }^{\circ} \mathrm{C}$ for $15 \mathrm{~min}$, brought to room temperature, mixed with $0.3 \mathrm{ml}$ isobutanol (by vigorous vortexing) and centrifuged at $15000 \mathrm{~g}$ for $3 \mathrm{~min}$. Then, the fluorescence of the upper isobutanol layer was measured at exitation/emission 535/550 nm against the isobutanoltreated sample $[0.15 \mathrm{ml}$ sample plus $0.15 \mathrm{ml} 20 \%$ TCA containing $0.33 \mathrm{M} \mathrm{HCl}$ and $0.02 \%(\mathrm{w} / \mathrm{v}) \mathrm{BHA}]$ and reagent blank $[0.15 \mathrm{ml}$ phosphate buffer plus $0.15 \mathrm{ml}$ TBH reagent containing $0.02 \%(\mathrm{w} / \mathrm{v})$ BHA]. Fluorescence was converted to malondialdehyde (MDA) equivalents (nM MDA in cytoplasm) from a standard curve using malonaldehyde bis(dimethyl acetal) (0-2 nM). Measurements were done in a Shimadzu RF-1501 spectrofluorophotometer set at low sensitivity and exitation/emission bandwidth of $10 \mathrm{~nm}$.

Measurement of sclerotial differentiation. The effect of the SOD mimetics on sclerotial differentiation (sclerotium production) was expressed as per cent differentiation, where $100 \%$ differentiation represents the number of SM sclerotia (approx. 850, 500 and 35 for $S$. minor, S. rolfsii and S. sclerotiorum, respectively) and dry weight for $R$. solani sclerotia (approx. $0.09 \mathrm{~g}$ ) formed per fungal colony in the absence of the SOD mimetics.

Statistical analysis. All data were reported as mean \pm SEM from at least triplicate experiments. The significance was determined using Student's unpaired $t$ test, with a value of $P<0.05$ considered to be significant.

\section{RESULTS AND DISCUSSION}

These data show that the direct indicator of oxidative stress, $\mathrm{O}_{2}{ }^{-}$, is directly involved in the differentiation of $S$. rolfsii, S. minor, S. sclerotiorum and $R$. solani throughout their developmental stages (Fig. 1) because radical sclerotiogenesis of these fungi is decreased in the presence of SOD mimetic scavengers. Specifically, sclerotial differentiation in S. rolfsii and S. sclerotiorum was decreased to nearly $50 \%$ by Tiron, while for S. minor and R. solani, sclerotial differentiation was decreased to 70 and $80 \%$, respectively, by TEMPOL (Fig. 2). The profiles of the SOD mimetic effect in the presence and absence of Tiron and TEMPOL on the decreased sclerotial differentiation showed that it is associated with the endogenous concentration of $\mathrm{O}_{2}{ }^{--}$. The levels of $\mathrm{O}_{2}{ }^{--}$, especially at the UD stage and during the transition stage (SI) between the undifferentiated and differentiated state, were decreased by $10-20 \%$ in the presence of the SOD mimetics. This decrease was less than the corresponding differentiation decrease (Fig. 3), suggesting that $\mathrm{O}_{2}{ }^{--}$may trigger additional molecular processes (e.g. involving its dismutation product $\mathrm{H}_{2} \mathrm{O}_{2}$ ) that may add up to its partial inhibition of sclerotial differentiation. The effectiveness of SOD mimetics in decreasing the levels of $\mathrm{O}_{2}{ }^{--}$was shown by the concomitant decrease (10-50\%) they caused in the activity of the intracellular SOD at the UD and SI developmental stages of these fungi, although this was not significant in all species (Fig. 4). The decreased oxidative stress (i.e. decreased $\mathrm{O}_{2}{ }^{-}$) that was caused by the SOD mimetics during these stages was supported by the similar level of decrease they also caused in lipid peroxidation (TBARS), which, in some but not all cases, extended into the SD and SM stages (Fig. 5).

This study dealt with two kinds of fungal developmental differences in relation to $\mathrm{O}_{2}{ }^{-}$-induced sclerotial differentiation: (i) those referring to the transition from the UD to the differentiated state (the initiation of which is designated SI), and these are the main focus of the paper; (ii) those referring to transitions within the differentiated state, designated SI, SD and SM stages. Differences between SI, SD and SM among the four strains studied seem to be

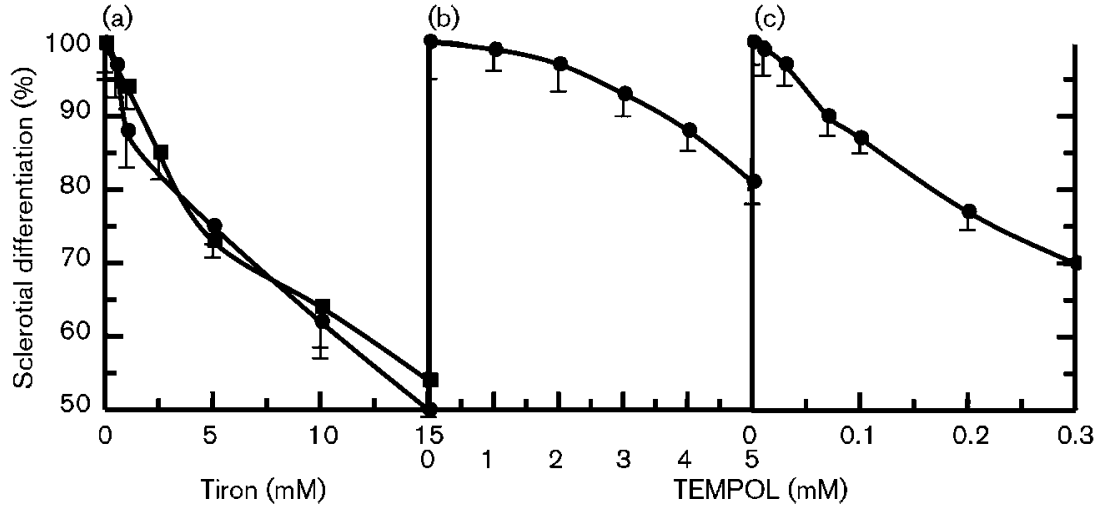

Fig. 2. Effects of the SOD mimetics Tiron and TEMPOL, tested up to concentrations not inhibiting fungal growth, on the per cent sclerotial differentiation of (a) S. rolfsii ( $\bullet$ ), S. sclerotiorum (ם), (b) R. solani and (c) S. minor (see Methods for definition). Bars, SEM. 


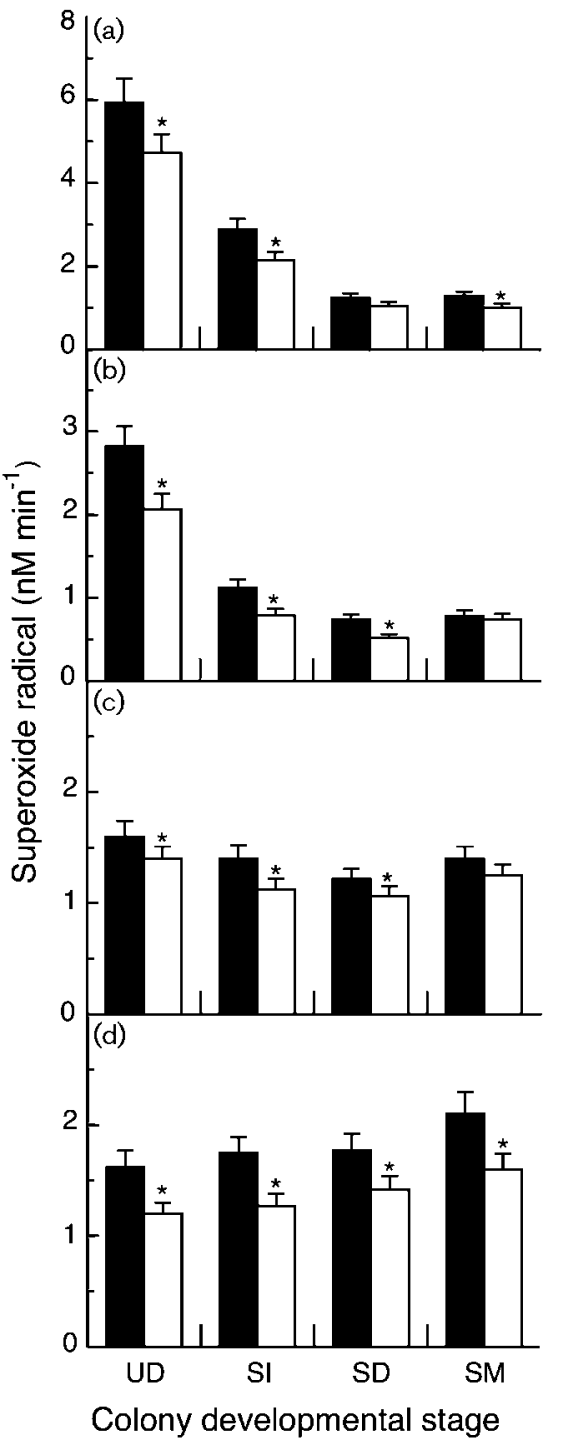

Fig. 3. Profiles of the rate of formation of $\mathrm{O}_{2}{ }^{--}$in the cytoplasm (equal to wet minus dry weight) in the end of the undifferentiated colony (UD) and in the sclerotium sub-stages SI, SD and SM of the differentiated colonies of (a) $S$. rolfsii and (b) $S$. sclerotiorum in the absence/presence of Tiron (15 mM) and (c) $R$. solani and (d) $S$. minor in the absence/presence of TEMPOL ( 0.3 and $5 \mathrm{mM}$, respectively). Filled and open bars show the absence/presence of SOD mimetics, respectively. Asterisks indicate that the difference between the $\mathrm{O}_{2}{ }^{-}$rate of accumulation in the absence and presence of the SOD mimetic is statistically significant; $P<0.05$.

more difficult to explain because they may be also related to the structural and metabolic differences that exist in their different sclerotial types. The SOD mimetics employed in this study shed light on the pro-oxidant role of $\mathrm{O}_{2}{ }^{--}$in the induction of sclerotial differentiation, although they do not simulate the $\mathrm{O}_{2}{ }^{--}$-scavenging of the native SOD to the full extent, due to their unknown intracellular concentration and site of action in the studied strains.

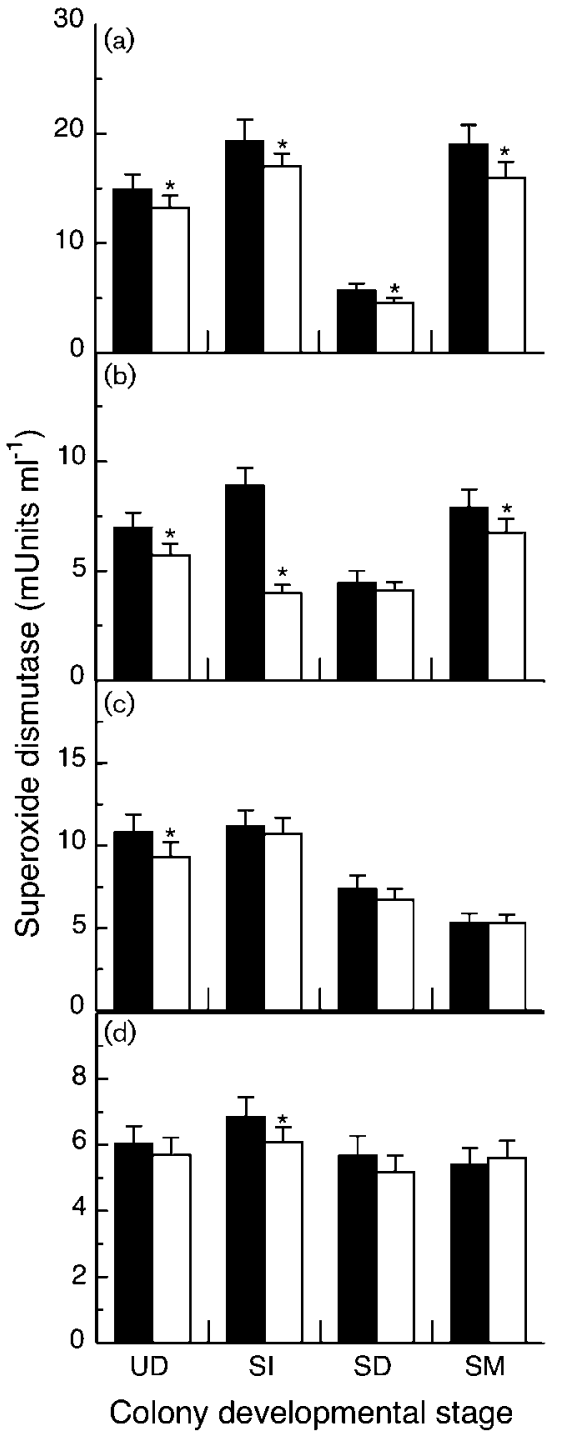

Fig. 4. Profiles of SOD activity in the cytoplasm (wet minus dry weight) in the end of the undifferentiated colony (UD) and in the sclerotium sub-stages SI, SD and SM of the differentiated colonies of (a) $S$. rolfsii and (b) $S$. sclerotiorum in the absence/presence of Tiron (15 mM) and (c) R. solani and (d) $S$. minor in the absence/ presence of TEMPOL ( 0.3 and $5 \mathrm{mM}$, respectively). Filled and open bars show the absence/presence of SOD mimetics, respectively. Asterisks indicate that the difference between SOD activity in the absence and presence of the SOD mimetic is statistically significant; $P<0.05$.

The relationship of $\mathrm{O}_{2}{ }^{-}$and SOD with differentiation has also been shown in Neurospora crassa, where $\mathrm{O}_{2}{ }^{-}$and other reactive oxygen species act as signal molecules for cytodifferentiation at certain stages of its development (Belozerskaia \& Gessler, 2006). Moreover, it was found that a manganese-type SOD-encoding gene is upregulated during conidiogenesis of the plant-pathogenic fungus Colletotrichum graminicola (Fang et al., 2002), and 


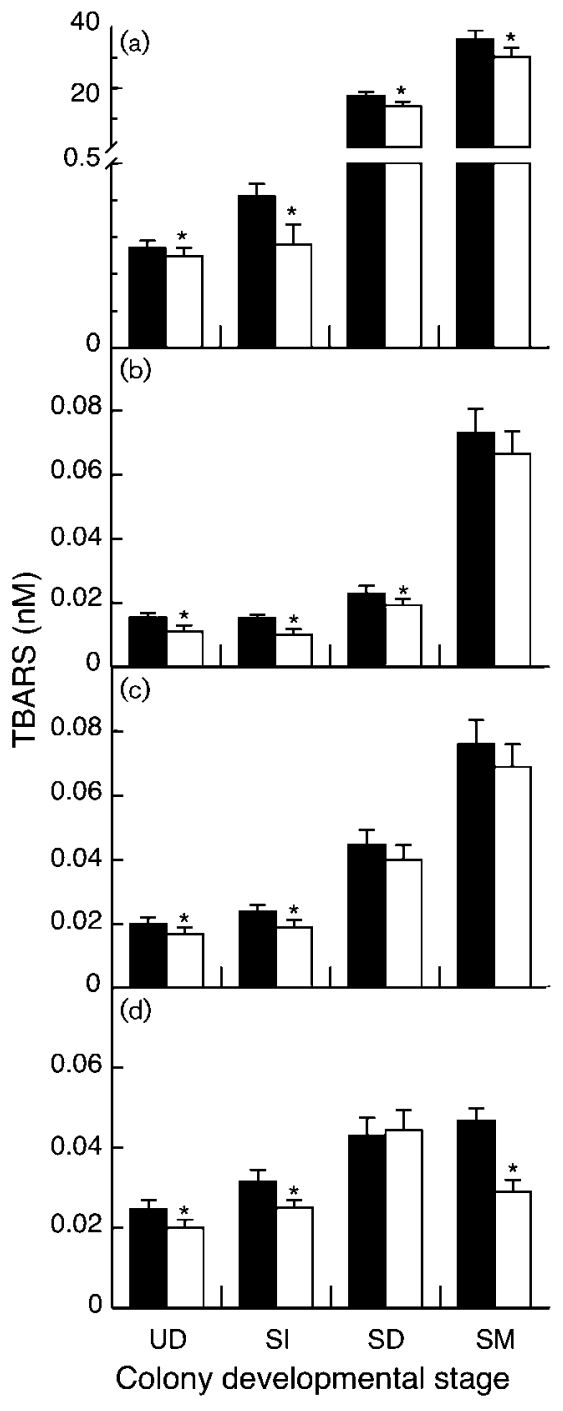

Fig. 5. Profiles of lipid peroxidation (expressed as TBARS concentration in the cytoplasm, equal to wet minus dry weight) in the end of the undifferentiated colony (UD) and in the sclerotium sub-stages SI, SD and SM of the differentiated colonies of (a) $S$. rolfsii and (b) $S$. sclerotiorum in the absence/presence of Tiron (15 mM) and (c) $R$. solani and (d) $S$. minor in the absence/ presence of TEMPOL ( 0.3 and $5 \mathrm{mM}$, respectively). Filled and open bars show the absence/presence of SOD mimetics, respectively. Asterisks indicate that the difference between lipid peroxidation in the absence and presence of the SOD mimetic is statistically significant; $P<0.05$.

Candida albicans, lacking the SOD gene, showed delayed hyphal growth necessary for the full virulence of the organism to be expressed (Hwang et al., 2002).

The present study shows that $\mathrm{O}_{2}{ }^{-}$in association with $\mathrm{SOD}$ regulates the sclerotial differentiation of $S$. rolfsii, S. minor, S. sclerotiorum and R. solani. Moreover, SOD mimetics can be used as potent fungicides against sclerotiogenic phytopathogenic fungi by causing a decrease in sclerotial production and sustaining fungi in their undifferentiated hyphal stage, which is more vulnerable to degradation by soil microorganisms.

\section{ACKNOWLEDGEMENTS}

This work was funded by the European Social Fund (ESF), Operational Program for Educational and Vocational Training II (EPEAEK II) and particularly the Program IRAKLEITOS.

\section{REFERENCES}

Belozerskaia, T. A. \& Gessler, N. N. (2006). Oxidative stress and differentiation in Neurospora crassa. Microbiology 75, 497-501.

Bridson, E. Y. \& Brecker, A. (1970). Design and formulation of microbial culture media. In Methods in Microbiology, pp. 229-295. Edited by J. R. Norris \& D. W. Ribbons. London: Academic Press.

Buege, J. A. \& Aust, S. D. (1978). Microsomal lipid peroxidation. In Methods in Enzymology, pp. 302-310. Edited by S. Fleisher \& L. Packer. New York: Academic Press.

Chet, I. \& Henis, Y. (1975). Sclerotial morphogenesis in fungi. Annu Rev Phytopathol 13, 169-192.

Chet, I., Henis, Y. \& Mitchell, R. (1967). Chemical composition of hyphal and sclerotial walls of Sclerotium rolfsii Sacc. Can J Microbiol 13, 137-141.

Chet, I., Henis, Y. \& Kislev, N. (1969). Ultrastructure of sclerotia and hyphae of Sclerotium rolfsii Sacc. J Gen Microbiol 57, 143-147.

Day, B. J., Shawen, S., Liochev, S. I. \& Crapo, J. D. (1995). A metalloporphyrin superoxide dismutase mimetic protects against paraquat-induced endothelial cell injury, in vitro. J Pharmacol Exp Ther 275, 1227-1232.

Fang, G.-C., Hanau, R. M. \& Vaillancourt, L. J. (2002). The SOD2 gene, encoding a manganese-type superoxide dismutase, is up-regulated during conidiogenesis in the plant-pathogenic fungus Colletotrichum graminicola. Fungal Genet Biol 36, 155-165.

Gardner, P. R., Nguyen, D. D. \& White, C. W. (1996). Superoxide scavenging by $\mathrm{Mn}(\mathrm{II} / \mathrm{III})$ tetrakis (1-methyl-4-pyridyl) porphyrin in mammalian cells. Arch Biochem Biophys 325, 20-28.

Georgiou, C. D. (1997). Lipid peroxidation in Sclerotium rolfsii: a new look into the mechanism of sclerotial biogenesis in fungi. Mycol Res 101, 460-464.

Georgiou, C. D., Patsoukis, N., Papapostolou, I. \& Zervoudakis, G. (2006). Sclerotial metamorphosis in filamentous fungi is induced by oxidative stress. Integr Comp Biol 46, 691-712.

Georgiou, C. D., Papapostolou, I. \& Grintzalis, K. (2008). Superoxide radical detection in cells, tissues, organisms (animals, plants, insects, microorganisms) and soils. Nat Protoc 3, 1679-1692.

Halliwell, B. \& Gutteridge, C. M. J. (1999). Free Radicals in Biology and Medicine, 3rd edn. Oxford: Oxford University Press.

Hwang, C.-S., Rhie, G., Oh, J.-H., Huh, W.-K., Yim, H.-S. \& Kang, S.-O. (2002). Copper- and zinc-containing superoxide dismutase $(\mathrm{Cu} /$ $\mathrm{ZnSOD}$ ) is required for the protection of Candida albicans against oxidative stresses and the expression of its full virulence. Microbiology 148, 3705-3713.

Kubota, S. \& Yang, T. J. (1984). Bis[cyclo(histidylhistidine)]copper(II) complex that mimicks the active center of superoxide dismutase has its catalytic activity. Proc Natl Acad Sci U S A 81, 3283-3286.

Le Tourneau, D. (1979). Morphology, cytology, and physiology of Sclerotinia species in culture. Phytopathology 69, 887-890. 
Lu, C., Bucher, G. \& Sander, W. (2004). Photoinduced interactions between oxidized and reduced lipoic acid and riboflavin (Vitamin B2). ChemPhysChem 5, 47-56.

MacKenzie, A. \& Martin, W. (1998). Loss of endothelium-derived nitric oxide in rabbit aorta by oxidant stress: restoration by superoxide dismutase mimetics. Br J Pharmacol 124, 719-728.

Misra, H. P. \& Fridovich, I. (1977). Superoxide dismutase: a photochemical augmentation assay. Arch Biochem Biophys 181, 308-312.

Mok, J. S., Paisley, K. \& Martin, W. (1998). Inhibition of nitrergic neurotransmission in the bovine retractor penis muscle by an oxidant stress: effects of superoxide dismutase mimetics. Br J Pharmacol 124, 111-118.

Patsoukis, N. \& Georgiou, C. D. (2007a). Effect of glutathione biosynthesis-related modulators on the thiol redox state enzymes and on sclerotial differentiation of filamentous phytopathogenic fungi. Mycopathologia 163, 335-347.

Patsoukis, N. \& Georgiou, C. D. (2007b). Effect of thiol redox state modulators on oxidative stress and sclerotial differentiation of the phytopathogenic fungus Rhizoctonia solani. Arch Microbiol 188, 225-233.

Patsoukis, N. \& Georgiou, C. D. (2008a). Thiol redox state and related enzymes in sclerotium-forming filamentous phytopathogenic fungi. Mycol Res 112, 602-610.

Patsoukis, N. \& Georgiou, D. C. (2008b). Thiol redox state and oxidative stress affect sclerotial differentiation of the phytopathogenic fungi Sclerotium rolfsii and Sclerotinia sclerotiorum. J Appl Microbiol 104, 42-50.
Patsoukis, N. \& Georgiou, D. C. (2008c). Differentiation of Sclerotinia minor depends on thiol redox state and oxidative stress. Can $J$ Microbiol 54, 28-36.

Townsend, B. B. \& Willetts, H. J. (1954). The development of sclerotia of certain fungi. Trans Br Mycol Soc 37, 213-221.

Willetts, H. J. (1971). The survival of fungal sclerotia under adverse environmental conditions. Biol Rev Camb Philos Soc 46, 387-407.

Willetts, H. J. (1978). Sclerotium formation. In The Filamentous Fungi, pp. 197-213. Edited by J. E. Smith \& D. R. Berry. New York: Wiley.

Willetts, H. J. (1997). Morphology, development and evolution of stromata/sclerotia and macroconidia of the Sclerotiniaceae. Mycol Res 101, 939-952.

Willetts, H. J. \& Wong, J. A.-L. (1980). The biology of Sclerotinia sclerotiorum, S. trifoliorum, and $S$. minor with emphasis on specific nomenclature. Bot Rev 46, 101-165.

Yamada, J., Yoshimura, S., Yamakawa, H., Sawada, M., Nakagawa, M., Hara, S., Kaku, Y., Iwama, T., Naganawa, T. \& other authors (2003). Cell permeable ROS scavengers, Tiron and Tempol, rescue PC12 cell death caused by pyrogallol or hypoxia/reoxygenation. Neurosci Res 45, $1-8$.

Zamora, R., Alaiz, M. \& Hidalgo, J. F. (1997). Feed-back inhibition of oxidative stress by oxidized lipid/amino acid reaction products. Biochemistry 36, 15765-15771.

Edited by: M. Tien 